\title{
LABORATORY TESTS REQUIRED TO REACH THE DIAGNOSIS IN PATIENTS WITH GROSSLY ELEVATED ESR
}

\author{
MD. ZAHIRUL HAQUE ${ }^{1}$, SAKI MD. ZAKIUL ALAM ${ }^{2}$, MESBAHUDDIN NOMAN $^{3}$, MD. ABU NASER \\ SIDDIQUE ${ }^{2}$, MA AZHAR $^{4}$
}

\begin{abstract}
:
This study was done in medicine indoor department of Rajshahi Medical College Hospital from January 2004 to March 2004. Consecutive 100 patients, who were found to have an ESR equal to or more than $100 \mathrm{~mm}$ in $1^{\text {st }}$ hour, were included in this study. Among them 56 were male and 44 were female. All of them were classified in five age groups. Haematological disorder appeared to be the most common cause (41\%) of marked ESR elevation; followed by infectious diseases $(36 \%)$ and connective tissue disorders (17\%). In 4\% cases the cause can not be elicited. In this study, most commonly done investigation was peripheral blood film (76 patients) and gave positive clue to diagnosis in 45\% cases. Bone marrow study was done in 53 cases and gave positive diagnosis in $69 \%$ cases. Other tests with high diagnostic yield were RA test (35\%), X-ray spine (62\%), Widal test (42\%), Splenic aspirate study for kala-azar (46\%), DAT for kala-azar (47\%), FNAC of lymph node (77\%), Pleural fluid study (100\%). Most of the patients have needed $3(46 \%$ patient) to 4 (27\% patient) special investigations along with routine investigations to reach the diagnosis.
\end{abstract}

\section{Introduction:}

Erythrocyte sedimentation rate (ESR) is a timehonoured, simple and inexpensive test. Raised ESR may be due to numerous aetiologies ranging from minor illness to serious disease. But grossly elevated ESR (equal to or more than $100 \mathrm{~mm}$ in $1^{\text {st }}$ hour) is an alarming situation and needs prompt diagnosis and treatment. The aetiologies of high ESR are difficult to find out and produce considerable diagnostic dilemma to the physician all over the world. Sometimes underlying pathology may be apparent from careful history, physical examination and simple laboratory investigation. Sometimes invasive and costly investigation is needed to reach the diagnosis.

The aetiologies of high ESR may vary from region to region. Such as, Kala-azar is prevalent in this part of the country, and a study done in Rajshahi Medical College Hospital showed that more than $36 \%$ of Kalaazar present with an ESR equal to or more than 100 $\mathrm{mm}$ in $1^{\text {st }}$ hour ${ }^{1,2}$. Unfortunately there is no study in our country regarding the aetiology and necessary laboratory tests to reach the aetiology of grossly elevated erythrocyte sedimentation rate. This study is carried out in Rajshahi Medical College Hospital to find out the common aetiologies of grossly elevated ESR and to list the minimum laboratory investigations to find out the cause.

\section{Materials and Methods:}

This was a prospective study which was carried out in medical indoor of Rajshahi Medical College Hospital from January 2004 to March 2004. Consecutive 100 patients, who were advised to test the ESR by their physicians for their complaints and found to have an ESR, equal to or more than $100 \mathrm{~mm}$ in $1^{\text {st }}$ hour, were included in this study. Out of 100 patients 56 were male and 44 were female. Patients were divided into five age groups having age range of less than 20 years, 20 to 30 years, 30 to 45 years, 45 to 65 years and more than 65 years respectively. The Westergren method of determining the ESR was used without correction for the haemoglobin value.

Detailed history, thorough clinical examinations were performed to elicit the cause. Total and differential

1. Assistant Professor, Department of Medicine, Rajshahi Medical College, Rajshahi

2. Assistant Professor, Department of Medicine, , Dhaka Medical College, Dhaka

3. Registrar, Nephrology Unit, Dhaka Medical College, Dhaka

4. Professor \& Head, Department of Medicine, Sir Salimullah Medical College, Dhaka

Correspondence : Dr. Md. Zahirul Haque, Assistant Professor, Department of Medicine, Rajshahi Medical College, Rajshahi 
count of WBC, Haemoglobin percentage, Urine R/M/ $\mathrm{E}$ and $\mathrm{X}$-ray chest P/A view were done in all cases. Special investigations like Comment on peripheral blood film, Bone marrow study, Splenic aspirate study for LD bodies, Widal test, Tuberculin test, Ultrasonography, X-ray skull and dorso-lumber spine, Lymph node biopsy, FNAC, ANF, RA test, Pleural, Ascitic and Cerebrospinal fluid study were done in special cases.

All patients were analyzed with male-female distinction along with age group distribution, socioeconomic condition, occupation, clinical presentation and possible diagnosis by using other investigations. The data were analyzed by SPSS version 10.

\section{Results:}

Among total 100 patients majority were male (56\%) and male to female ratio was 1.27:1 (Tabel-I).

\section{Table-I}

Sex Distributions of the patients

\begin{tabular}{lc}
\hline Sex & Number \\
\hline Male & 56 \\
Female & 44 \\
\hline
\end{tabular}

Majority of the male patients (27\%) were within 31 45 age group and most of the female patients (36\%) were within 21 - 30 age group (Tabel-II).

Table-II

Age Distribution of the patients

\begin{tabular}{lcc}
\hline Age group & \multicolumn{2}{c}{ Number of Patients } \\
& Male & Female \\
\hline$<20$ & 8 & 12 \\
$21-30$ & 10 & 16 \\
$31-45$ & 15 & 6 \\
$45-65$ & 13 & 8 \\
$>65$ & 10 & 2 \\
\hline
\end{tabular}

Haematological disorder appears to be most common cause (41\%) of marked ESR elevation; followed by infectious diseases (36\%) and connective tissue disorders (17\%). In $4 \%$ cases the cause can not be elicited. No cause can be found in the $4 \%$ of patients in this study (Tabel-III).
Table-III

Diagnoses of 100 patients with ESR e"100 $\mathrm{mm}$ in $1^{\text {st }}$ hour

\begin{tabular}{lcc}
\hline Diagnoses & Male & Female \\
\hline Haematological Disorders (total 41): & & \\
Acute myeloblastic leukaemia & 5 & 7 \\
Acute lymphoblastic leukaemia & 3 & 2 \\
Aplastic anaemia & 5 & 2 \\
Lymphoma(Hodgkin's/Non-Hodgkin's) & 5 & 2 \\
Multiple myeloma & 6 & 0 \\
Immune haemolytic anaemia & 2 & 1 \\
Myelodysplastic syndrome & 1 & 0 \\
Infections (total 36): & & \\
Pulmonary tuberculosis & 5 & 3 \\
Extar-pulmonary tuberculosis & 4 & 4 \\
Kala-azar & 5 & 3 \\
Enteric fever & 1 & 1 \\
Liver abscess & 2 & 1 \\
Septic arthritis & 1 & 1 \\
Fileriasis & 0 & 1 \\
Bacterial meningitis & 1 & 1 \\
Cerebral malaria & 1 & 0 \\
Septicaemia & 0 & 1 \\
Connective tissue diseases (total 17): & & \\
Rheumatoid arthritis & 3 & 10 \\
SLE & 0 & 2 \\
Rheumatic fever & 1 & 1 \\
Chronic liver disease(2): & 2 & 0 \\
No Diagnosis (4): & 3 & 1 \\
\hline
\end{tabular}

The most commonly done investigation was peripheral blood film (76 patients) and gave positive clue in $45 \%$ cases. Bone marrow study was done in 53 cases and gave positive diagnosis in $69 \%$ cases. Serum creatinine and Ultrasonography of whole abdomen were least rewarding and give positive result in only $6 \% \& 17 \%$ cases respectively. Other tests with high diagnostic yield were RA test (35\%), X-ray spine (62\%), Widal test (42\%), Splenic aspirate study for kala-azar (46\%), DAT for kala-azar (47\%), FNAC of lymph node (77\%), Pleural fluid study (100\%) (Table-IV). 
Table-IV

Most common tests done to reach the diagnosis with the percentage of positive yield

\begin{tabular}{lccc}
\hline Test & Done in & Positive in & Percent of positive \\
\hline Comment on peripheral blood film & 76 & 34 & $45 \%$ \\
Bone marrow aspiration and study & 53 & 37 & $69 \%$ \\
Serum creatinine & 48 & 3 & $6 \%$ \\
Ultrasonography of abdomen & 34 & 6 & $17 \%$ \\
RA test & 31 & 11 & $35 \%$ \\
Widal test & 19 & 8 & $42 \%$ \\
DAT for kala-azar & 17 & 8 & $47 \%$ \\
X-ray spine & 16 & 10 & $62 \%$ \\
Splenic aspiration \& study for LD bodies & 13 & 6 & $46 \%$ \\
Anti nuclear factor & 10 & 2 & $20 \%$ \\
FNAC of the lymph node & 9 & 7 & $77 \%$ \\
Pleural fluid study & 6 & 6 & $100 \%$ \\
Blood for malarial parasite & 4 & 1 & $25 \%$ \\
\hline
\end{tabular}

Table $-\mathrm{V}$ shows that 46 patient needed 3 and 27 patients needed 4 special investigations along with routine investigations to reach the diagnosis.

\section{Table-V}

Number of tests required to reach the diagnosis

\begin{tabular}{cc}
\hline Patient's number & $\begin{array}{c}\text { Number of special } \\
\text { tests to reach diagnosis }\end{array}$ \\
\hline 16 & $\leq 2$ \\
46 & 3 \\
27 & 4 \\
11 & $\geq 5$ \\
\hline
\end{tabular}

\section{Discussion:}

Erythrocyte sedimentation rate (ESR) is a non-specific indicator of diseases. Though the usefulness of ESR has decreased as new method of evaluating diseases have been developed, it is still useful as "sickness index" in persons who have non-specific changes in health status and a moderate probability of underlying disease $^{3}$. An ESR value exceeding $100 \mathrm{~mm} /$ hour has a $90 \%$ predictive value for serious underlying disease, and a minimal number of tests usually reveal the cause $^{3}$.

Grossly elevated ESR ( $>100 \mathrm{~mm}$ in $1^{\text {st }}$ hour) is a common finding all over the world. There are numerous aetiologies of marked ESR elevation. All the aetiologies in our country may not be as same as in other part of the world; there should be some variation. This study was conducted on 100 cases with ESR equal to or more than $100 \mathrm{~mm}$ in $1^{\text {st }}$ hour selected from the medicine department of one of the medical college hospital in northern Bangladesh.

In the present study, majority of the patients were male (56\%). No other study is available regarding the male: female ratio among the patients with grossly elevated ESR. However, this may be due to the fact that male patients present themselves in hospitals more commonly than female. General attitude of our female toward hospital admission which they tend to avoid may be another reason.

In this series, majority of the male patients (27\%) were within 31 - 45 age group and most of the female patients (36\%) were within 21 - 30 age group (TableII). One of the common cause of marked ESR elevation is connective tissue diseases, which are most prevalent in the young female patients. This may be cause of higher percentage of female patients of younger age group.

In this study, Haematological disorder appears to be the most common cause (41\%) of marked ESR elevation; followed by infectious diseases (36\%) and connective tissue disorders (17\%). In $2 \%$ cases the cause is chronic liver disease. In $4 \%$ cases the cause can not be elicited. Among the all patients $30 \%$ cases 
are haematological malignancies (i.e. acute myeloblastic and lymphoblastic leukaemia, lymphomas, multiple myeloma). There is no other case of malignancy in this study. This result is little bit different from that of the previous other studies. In a study in Zimbabwe ${ }^{4}$, infection was the most common cause (46\%), followed by malignancy ( $25 \%)$, connective tissue disorder (17\%), renal disease (8\%) and liver disease (5\%). Pneumonia was the most common infection. In our study, we have found tuberculosis (pulmonary \& extra pulmonary) as the most common infection followed by kala-azar. Lluberas-Acosta G \& Schumacher HR Jr. $(1996)^{5}$ showed that most common cause of ESR e" $100 \mathrm{~mm}$ in $1^{\text {st }}$ hour was infection (47\%). The other diagnosis in that study was malignancy $(17 \%)$, rheumatic disease $(33 \%)$, renal disease (27\%) and miscellaneous problems (42\%). 66\% patients had more than one diagnosis.

A study done by Fincher RM \& Page MI (1986) ${ }^{6}$ also revealed the most common cause of markedly raised ESR was infection (33\%) with malignant and renal disease each responsible for $17 \%$ and inflammatory disorder for $14 \%$. In $10 \%$ no cause was identified.

It is surprising not to see the infectious disease as the commonest diagnosis in patients with markedly elevated ESR in this study. Infectious disease is more prevalent in a developing country like Bangladesh, and kala-azar, one of the known causes of marked ESR elevation, is endemic in this region. One possible explanation of this result may be the site of this study which was done in medicine unit of Rajshahi Medical College Hospital. It is a tertiary level referral hospital. Most of infections can be diagnosed and treated at primary and secondary level, such as, at union, upazila or district level. Only those with complications or with diagnostic dilemma are being referred to this hospital.

This may also be the possible explanation why haematological disorders are the most prevalent diagnosis among these patients. Haematological diseases are difficult to diagnose and treat in the upazila and the district level and most of them are referred to this tertiary referral hospital. Moreover, Haemopoitic malignancy cases getting repeatedly admitted for blood transfusion or therapy might have significantly increased their number in this study thereby making infectious diseases as second common cause of marked elevation of ESR.

Renal disorder was found to be an important cause of markedly raised ESR in most of the studies. But here, we do not get any of them. Probably this is due to the separate nephrology unit in Rajshahi Medical College Hospital where all the renal patients are admitted.

Connective tissue diseases are responsible for $17 \%$ cases in this study. This is comparable to the Zimbabwean study (17\%) but reasonably less than some of the European and American studies ${ }^{7}$ where infectious diseases are less common and percentage of connective diseases is higher.

No cause was found in the $4 \%$ of patients in this study. This is less than other studies where it varied from $5 \%{ }^{8}$ to $10 \%{ }^{6}$. The rate of positive diagnosis is high in our study. This is possibly due to this study which has been done on symptomatic patients admitted in the hospital. Most other studies included both symptomatic and asymptomatic patients.

In this study, we see some investigations are with high positive result, and some commonly used first line tests (e.g. Urine R/M/E, Serum creatinine, Ultrasonography) are with low diagnostic utility. We can minimize the number of investigation if you we advise initially for the tests which are with high positive result. Then other tests can be advised if initial reports are negative and history and physical examination suggest.

Here, we can recommend some first line investigations in patients with very high ESR. This may be slightly different from those recommended by previous literature ${ }^{6,8}$. Montoux test may be confusing in our country where prevalence of asymptomatic tuberculous infection is high. Plasma and urine protein electrophoresis needs sophisticated laboratory and not available in most of the places. Following investigations can be recommended in such patients in our country:

Comment on peripheral blood film

Bone marrow aspiration and study

$\mathrm{X}$-ray chest $\mathrm{P} / \mathrm{A}$ view

RA test

DAT for kala-azar

X-ray spine and skull

Splenic aspiration \& study for LD bodies

Anti nuclear factor

FNAC of the lymph node

Pleural fluid study 


\section{Conclusion:}

Simple, non-invasive, widely available laboratory tests may yield the diagnosis in majority of the cases with high elevation of ESR. We can avoid costly, sophisticated investigations if we give emphasis on careful history taking and meticulous physical examination.

Though this is a tertiary-hospital study which may not truly reflect the community, all level of practitioners must be aware of this hospital picture. This study may help them in approaching their patients with markedly elevated ESR in a cost effective way, thereby reducing the cost as well as suffering of poor patients of this country.

\section{References:}

1. Chowdhury MAJ, Ahsan HAMN, Rafiquddin AKM, Hussain A. Erythrocyte sedimentation rate in Kalaazar. TAJ 1993; 6:29-30

2., Rahman H, Siddiqui AB. Journal of Bangladesh College of Physicians and Surgeons. 8 (1): 18-28.

3. Bridgend M. The erythrocyte sedimentation rate. Still helpful test when used judiciously. Post-grad Med 1998;103(5):257-62,272-4.
4. Stein CM, Xavier R. Extreme elevation of the erythrocyte sedimentation rate in patients admitted to a general medical ward in Harare, Zimbabwe. J Trop Med Hyg 1989; 92(4): 259-62.

5. Lluberas-Acosta G, Schumacher HRJ: Markedly elevated erythrocyte sedimentation rates: consideration of clinical implications in a hospital population. Br J Clin Pract 1996; 50:138-142.

6. Fincher RM. Page MI. Clinical significance of extreme elevation of the erythrocyte sedimentation rate. Arch Int Med 146(8):1581-3.

7. Bedell, Bush SE, Booker T. Erythrocyte sedimentation Rate: From Folklore to Fact. The American Journal of Medicine 1985; 78: 1001-7.

8. Stevens D, Tallis R, Hollis S: Persistent grossly elevated erythrocyte sedimentation rate in elderly people: one year follow-up of morbidity and mortality. Gerontology 1995; 41:220-6.

9. Brigden M. Clinical utility of the erythrocyte sedimentation rate. American Family Physicians 1999. 